\title{
EPISTEMOLOGÍA Y POLÍTICA EN EL DISCURSO PEDAGÓGICO
}

\author{
A. RUIPÉREZ SÁNCHEZ. D. NAVARRO OR'TIZ, \\ M. 'T. BUEÑO GUTIÉRREZ, P. SÁNCHEZ VERA
}

\section{Introducción}

Se trata, en este breve escrito, de exponer esquemáticamente las posiciones epistemológicas sobre la Pedagogía y las consecuencias previsibles que, en el orden político, se derivan de ellas.

Cuando se trata de Teoría de la Educación, no se puede repetir a los autores "que cultivan la cómica ilusión de que las aduanas epistemológicas protegen su esfera de toda intrusión de la política ${ }^{\mathrm{i}}$. Es más, breve. mente, trataremos de demostrat que la po. sición epistemológica tiene un correlato político insoslayable cuya ignorancia supone enfrentarse a la Pedagogía desde un "obs" táculo epistemológico" que la desvirtúa.

Tres son las opciones que suelen tomarse respecto a la Teoría de la Educación:

a) Considerar la Pedagogía como ámbito teórico inútil o ilegítimo.

b) Adscribirse al cientifismo, desechando la presencia de lo ideológico en "la ciencia de la educación'”.

c) Pensar que la Teoría de la Educación tiene un estatuto propio que hay que dilucidar (posición que asumimos nosotros).

\section{La arbitrariedad pedagógica supone la arbitrariedad política}

La Pedagogía se niega desde dos ópticas distintas, pero que tienen consecuencias políticas idénticas: al negar la legitimidad de la reflexión teórica en el hecho social que es la práctica educativa, establecemos la arbitra* riedad política como criterio dominante.

Se niega la teoría educativa desde una posición pragmática, fuertemente arraigada en los profesionales de la enseñanza, afirmando el carácter de "arte» de la misma. Para dicho "arte" se suponen cualidades innatas y aportes meramente experimentales.

Olvidan quienes así se expresan que no existe práctica educativa sin un informe teórico, aunque esto no se asuma de forma cons-

${ }^{1}$ LOURAU, R., El anälisis institucional, Buenos Aires, 1975. Amorrortu. ciente. Semejante posición transforma, por tanto, a los educadores en artesanos inconscientes. Por otra parte, como señala Jesús Palacios: "Es obvio que no se trata de copiar sin más modelos ya acabados, pero no es menos claro que ignorar esos modelos, esas alternativas fundamentales en la reflexión y la práctica de otros es privarse a sí mismo de la riqueza acumulada por esa reflexión y esa práctica»².

Más profunda es la crítica de los que rechazan la Pedagogía en base al argumento de que carece de ámbito propio de actuación. La educación podría ser abordada desde la Psicología, Filosofía, Sociología, didácticas especiales. Todo proyecto de hacer coherentes los datos aportados por esas materias es ilegítimo. La consecuencia de ello es explicitada por Bourdieu, Passeron y Saint Martin cuando escriben que "rechazar la $\mathrm{Pe}$ dagogía equivale a dotarse de alumnos iguales en deberes ante la lengua universitaria y, por lo mismo, condenarse a atribuir a la capacidad innata buen número de desigualdades que son primordialmente desigualda. des sociales»" ${ }^{3}$.

Esta negativa de validez respecto a la Teoría de la Educación desborda el marco del sistema de enseñanza y, en el límite, se pue. de extraer la siguiente conclusión política: "En la medida que no exista un cuerpo or" gánico de leyes que describan, expliquen y permitan predecir los fenómenos educati. vos, es decir, en la medida que no exista un conjunto articulado de conocimientos científicos, coherentes, contrastables y válidos acerca de la educación, el Estado podrá seguir ejerciendo el dominio absoluto del aparato ideológico, sin peligrosos competidores, pues, en tanto se mantengan al nivel de opinión los problemas educativos, más fácilmente podrán ser manipulados ideológicamente $)^{4}$.

2 PaLACIOS. J., "Transformar la escuela", Cuadermos de Pedizogía, 1979, no 51. La misma tesis puede verse más desarrollada en su libro La ctestión escolar, Barcelona. 1979, Laia.

3 Bourdieu. PASSERON. SAINT MARTIN. Rapports pédago. giques et communication, París, 1965, Mouron, p. 30.

4 SANTAMARİA, R., eldeología, ciencia y praxis de la educacións, en Varios, Epistemología y educación, Salamanca, 1978, Sigueme. p. 121 


\section{Cientifismo pedagógico y peligro totalitario}

De manos del positivismo llega a la 'Teoría de la Educación la posición cientifista. Tras - la palabra ciencia, se trata de presentar como reutrales las decisiones educativas. Los in tereses políticos se enmascaran en lenguaje tecnocrático.

Desde la epistemología podemos rechazar todo intento de eliminar lo ideológico en la actividad científica, pues como afirman Castell e Ipola: "la ideología designa un sistema de representaciones, nociones, gustos, actitudes, etc. cuyo efecto propio es asegurar la cohesión social, en general, mediante la regulación del vínculo que une los individuos a las tareas que les corresponden en virtud de su posición en la estructura social. En este último sentido, la ideología es un componente «indispensable» de toda práctica social (de la que forma parte la práctica científica) $)^{3}$.

Esa «indispensable» presencia de lo ideológico en "toda» práctica científica y con mucha más razón en los discursos sobre la práctica social que llamamos educación, no atenta contra la validez teórica o legitimidad de éstos. Es la negación de esa presencia lo que vuelve ilegítimas y peligrosas las teoriza. ciones educativas.

La ilegitimidad epistemológica de las pedagogías tecnocráticas es satirizada magis. tralmente por Gustavo Bueno, mostrando sus torpes planteamientos ideológicos y cor" porativos, así como la generosidad para con ellos del poder: «los sofistas se reproducirán siempre, precisamente porque la multitud y los gobiernos necesitan estos científicos de la personalidad, estos maestros de la virtud. Por ello, tampoco negamos a los sofistas su función social. En la Edad Media, por ejem plo, la función de los sofistas ha sido desempeñada por el clero (...) en nuestro siglo (...) los sofistas renacen bajo formas nuevas (...) estos nuevos sofistas son ahora los que se autodenominan científicos de la educa. ción (...). Y es pura propaganda gremial el presentar planes generales de educación cien.

5 CASTELLS, M., DE IPOLA, E., Metodología y epistemolo. gia de las ciencias sociales, Madrid, 1975. Ayuso, p. 149. tíficamente fundados: las relaciones entre las diversas ciencias del aprendizaje, si las hay, no pueden ser científicas. $Y$, sin embargo, los nuevos sofistas logran convencer a los estados y a los ciudadanos de su importancia, y obtienen asignaciones económicasin ${ }^{6}$.

No obstante, el cientifismo pedagógico no supone sólo legitimidad teórica o arropamiento de intereses gremiales, sino que tiene una traducción política de claro peligro totalitario. Este peligro es señalado por $\mathrm{Fu}-$ llat cuando afirma: "Estamos convencidos de que un proyecto educativo que se presenta como totalmente científico constituye una estafa a la democracia, consistiendo en imponer dogmáticamente bajo disfraz científico lo que no va más allá de ser una concepción de la existencia entre muchas otras. En tal supuesto, a la ciencia se le hace jugar un papel ideológico, justificador y encubridor, por tanto, del apetito y del talante totalitarios"?

\section{Sobre el estatuto de la pedagogía}

A la vista de lo anterior, nos parece claro que hay que huir tanto de la negación de toda validez de la teoría educativa, como de la afirmación de su cientificidad a ultran$z a$, rechazando la presencia de elementos ideológicos.

El problema se sitúa entonces en la clarificación del estatuto propio de la Pedagogía en la actual coyuntura histórica, y en el descubrimiento de las relaciones que dicha teoría mantiene con la organización política de la sociedad.

Partimos de un triple hecho:

- No existe práctica educativa sin una información teórica.

- Esa información teórica incluye elementos ideológicos.

- La presencia de lo ideológico trae como consecuencia el pluralismo pedagógico.

6 Platón, Protágoras, Oviedo, 1980, Pentalfa. Traduc. ción de Velarde Lombraña. La cita corresponde a la intro. ducción de Gustavo Bueno, pp. 82 y 83.

7 Fullat, O., Filosofias de la educaciön, Earcelona, 1978, Ceac, p. 1. 
En base a ello, podemos preguntarnos sobre la legitimidad de los modelos pedagógi* cos, tanto de los establecidos sólo a nivel teórico, como de los que operan de forma dominante en los sistemas de enseñanza establecidos. Veremos que toda epistemolo. gía de la educación, en cuanto interrogante sobre la fundamentación de las teorías que la informan, deberá recoger tanto lo interno a esas teorías, como lo externo - factor político-que explica su legitimidad.

Para esta explicación proponemos tres con* ceptos que nos permiten recoger tanto los aspectos internos como los externos de la legitimación pedagógica: "ideología teórì ca», «ideología científica», "obstáculo epis" temológico». Conceptos que aplicaremos a dos tipos de discurso educativo:

- El oficial, legítimo y legitimador.

- El alternativo, ilegítimo e ilegitimador.

Ocurre, con demasiada frecuencia, que formulaciones teóricas muy discutidas racionalmente, operan de forma dominante en los sistemas oficiales de enseñanza. La explicación de su mantenimiento la encontramos si vemos en ellas "ideologías teóricas", es de. cir, sistemas ideológicos reconocidos socialmente como prácticas científicas merced a su inscripción en aparatos de Estado ${ }^{8}$.

El aparato en que se inscriben esas pedagogías es, principalmente, el escolar, del que reciben su legitimidad y a su vez legitiman.

Desde esta perspectiva, es posible entender la terca resistencia a desaparecer de principios pedagógicos invalidados racionalmente y que siguen manteniendo la rutina educativa de muchas escuelas. La utilidad de su permanencia, que no es posible encontrar en términos de racionalidad abstracta, aparece en forma de utilidad política: son ideologías de poder.

Esa legitimidad prestada políticamente a determinadas teorías pedagógicas (que supone la ilegitimación práctica de otras) es traducida por Bourdieu y Passeron como «autoridad pedagógica».

La autoridad pedagógica se fundamenta,

8 Castells, lpola, op. cit., p. 153. tanto en la delegación estatal de poder como en su capacidad para simular una total autonomía respecto a factores extraños a la ins. titución escolar'.

Debido a su absoluta subordinación a la sociedad política - independientemente de su validez teórica- llamamos a estas "pedagogías oficiales", "legítimas» -en términos de status social y político-y "legitimadoras" de las coyunturas sociales y de sus conformaciones políticas.

Frente a estos discursos pedagógicos, encontramos otros que llamamos «alternativos», «ilegítimos» e "ilegitimadores», que parten de las implicaciones políticas intrínsecas a sus principios.

Para su examen proponemos, siguiendo a Canguilhem, el concepto de "ideología científica", o teorización, que sin ser ciencia no supone obstáculo para su establecimiento y tiende (otra cosa es que lo consiga) a ello'.

Son teorías que se reconocen en la propuesta de Debesse: "A mi parecer, se podrían eliminar muchas prevenciones, hacex desaparecer muchos prejuicios, si se admitiera que la pedagogía no es ninguna receta, sino una investigación $\mathrm{n}^{11}$.

La adjetivación de estas pedagogías como alternativas o ilegítimas, proviene de su establecimiento al margen de los aparatos de Estado, permitiendo así una discusión en términos teóricos sobre su validez, vista su ilegitimidad respecto al ámbito oficial. No son legítimas porque una de sus funciones primordiales es establecer la crítica frente a las oficiales, tratando de desenmascararlas mediante la discusión teórica y práctica.

Con respecto a esta función crítica, aparece como pertinente la formulación del con" cepto de "obstáculo epistemológico» o «re" sistencias intelectuales que bloquean o desnaturalizan la producción de conocimientos, debido a que se establece una relación ima.

9 BOURDIEU. P.; PASSERON, J.C., La reproducción, Barcelona, 1977, Laia

10 CANGUilheM. G., "¿Qué es una ideología cientifica?», Organon del Instituto Polaco de Historia de las Ciencias y las Técnicas, 1970, $\mathrm{n}$ : 7. Traducción de Luis Carlos Alboleda en texto fotocopiado sin citar procedencia.

11 DEBESSE, M., Introducción a la pedagogía, Batcelona, 1972, Oikos-Tau, p. 18. 
ginaria del científico con su propia práctica» ${ }^{12}$.

Son precisamente estos obstáculos los primeros que ha de identificar toda pedagogía alternativa, apareciendo actualmente como principal la pretensión de "neutralidad fren" te a lo político". Dicho obstáculo, por las razones anteriormente aludidas, convierte a ciertos discursos pedagógicos en ideologías de poder, imposibilitando su desarrollo.

Debido a esto, el tecnocratismo educativo se convierte en barrera a superar por toda teoría pedagógica que aspire a formularse en términos de investigación racional y no de imposición política.

Un modelo de teoría educativa que asuma su status de ideología científica se podría encontrar formalizado en Moore ${ }^{13}$ cuando, desde su opción analítica, distingue entre teorías científicas y prácticas, encuadrando la Pedagogía en estas últimas.

La estructura propuesta es la siguiente:

12 CAstell, IPOLA op. cit., p. 145 . El texto remite a Ba. chelard como formulador del concepto de obstáculo epistemológico y de su génesis. Tras la calificación de ideología científica que hemos hecho para ciertas teorías de la educa. ción, hemos mantenido el têrmino científico por respeto a la cita, pero advertimos que debe leerse pedagogo o teótico de la educación.

13 MOORE. T.W. Introducción a la teoria de la educa. ción, Madrid, 1980, Alianza. $\rightarrow \mathrm{P}$ es deseable como finalidad.

- En las circunstancias actuales, Q es la forma más efectiva de conseguir $P$.

Luego hagamos lo que $\mathrm{Q}$ implica.

En toda Teoría de la Educación son su* puestos específicos:

- La determinación de los fines.

- Establecimiento de la naturaleza humana.

- Naturaleza del conocimiento y métodos apropiados para transmitirlo.

Esta estructura aunque impugnada por diversos autores ${ }^{14}$, permite, en nuestra opinión, establecer criterios de validación o invalidación de las teorías de la educación, en base a supuestos racionales de orden moral (discusión de los fines), empíricos (naturaleza humana y del conocimiento) y de coherencia entre supuestos y conclusiones.

Es decir, podemos dilucidar la suerte teón. rica de determinados modelos pedagógicos. La suerte práctica es algo que escapa a Moore y a nosotros, en la medida en que entra de lleno en el campo de las relaciones sociales de orden general, que son las que determinan las coyunturas políticas.

14 QuINTANILLA, «E] estatuto epistemológico de las ciencias de las ciencias de la educación , en Epistemologia y educación, op, cit., PP. 100 y $10 \mathrm{~L}$. 